\title{
The evolution of hypovolemic and euvolemic hyponatremia coincides with an inflammatory status in patients with COVID-19
}

JORGE GABRIEL RUIZ SANCHEZ ( $\square$ gajo_Saru@hotmail.com )

Hospital Clínico San Carlos https://orcid.org/0000-0003-1305-9354

Pamela Chávez-Díaz

Hospital Universitario Quirónsalud Madrid: Hospital Universitario Quironsalud Madrid Jersy Cárdenas-Salas

Fundación Jiménez Díaz: Hospital Universitario Fundacion Jimenez Diaz

\section{Research Article}

Keywords: hyponatremia, COVID-19, SARS-CoV-2, inflammation

Posted Date: May 19th, 2021

DOI: https://doi.org/10.21203/rs.3.rs-519751/v1

License: (c) (i) This work is licensed under a Creative Commons Attribution 4.0 International License.

Read Full License 


\section{Abstract}

\section{BACKGROUND}

Hyponatremia is a frequent electrolytic disorder in hospitalized patients with Coronavirus Disease 2019 (COVID-19). Inflammatory status could be associated with hyponatremia in patients with COVID-19. We evaluate the hospital evolution of hyponatremia and inflammation markers in COVID-19 patients.

\section{METHODS}

A case-series of adult patients with COVID-19 pneumonia and hyponatremia at admission were included and retrospectively followed during hospitalization. Data of the volemic status, general characteristics, inflammation, and clinical outcomes, were collected and analyzed. Comparative and multivariate analyzes were developed, and Hazzard ratio (HR) with 95\%-confidence intervals (95\% Cl) were calculated.

\section{RESULTS}

49 patients with hyponatremia followed, 32 (65.3) were male, and 22 (44.9\%) euvolemic. Mean age: 69.9 \pm 14.7 years. From the $100 \%$ of patients with hyponatremia at admission, only $26.2 \%$ remained hyponatremic at the 7th -10th hospitalization day. Improvement in serum sodium ( $\mathrm{SNa}$ ) coincided with improvement in inflammatory markers during hospitalization, as well as a decrease in the rate of hyponatremia. A lower SNa at admission was independently associated with mortality (HR: $12.23,95 \% \mathrm{Cl}$ : 2 to 25.6$)$.

CONCLUSION

Both admission hypovolemic and euvolemic hyponatremia in COVID-19 patients occurred in a inflammation status, and improved as inflammation markers decreased.

\section{Introduction}

Hyponatremia is observed in $19.7 \%$ of hospitalized patients(1) and is associated with an increase in hospital mortality $(1,2)$.

It is known that pneumonias are related with the development of hyponatremia via non-osmotic stimulation of the arginine-vasopressin release. Hyponatremia in patients with pneumonia is often euvolemic, and caused by the syndrome of inappropriate secretion of antidiuretic hormone (SIADH), which has been observed in approximately a third of hospitalized pneumonia patients(3). The study complied with accepted standards of good clinical practice of the World Medical Association Declaration of Helsinki, in accordance with the guidelines of the local Research Ethics Committee of the Hospital Clínico San Carlos 
Pneumonia caused by Coronavirus disease 2019 (COVID-19) is often accompanied by hyponatremia. The prevalence of hyponatremia in COVID-19 patients has been reported in a range from 9.9-30\% (4-7). The mechanisms behind its etiopathogenesis remain unclear. SIADH has been suggested as a frequent cause(8). Berni et al. showed an inverse relationship between levels of serum sodium (SNa) and interleukin-6 (IL-6) in COVID-19 patients(9), proposing an inflammatory via implicated in the development of hyponatremia. However, inflammatory mechanisms on the development of hyponatremia would be expected when the latter is caused by $\operatorname{SIADH}(10)$. Whether an inflammatory status is also implicated in other volemic types of hyponatremia has not been elucidated.

We reviewed COVID-19 patients with hyponatremia and analyzed the relationship between their inflammatory markers with the evolution of the SNa during the hospitalization, in addition to describe the main clinical characteristics that accompanied hyponatremia.

\section{Methods}

It is a retrospective study of a series of consecutive cases of adult patients with COVID-19 pneumonia who had hyponatremia at hospital admission and were followed during the hospitalization. COVID-19 pneumonia was confirmed by a positive reverse-transcriptase polymerase chain reaction test plus clinical and/or radiological picture of pneumonia. All patients were admittance during April 1st to April 30th 2020 in three wards of different tertiary hospitals of Madrid, Spain, where the "COVID-19 teams" -conformed by physicians of different medical specialties- attended COVID-19 patients during the first wave of the pandemic. Each of the authors of the current study was part of a COVID-19 team of her/him respective hospital ward during this period.

Hyponatremia was defined as a SNa $<135 \mathrm{mmol} / \mathrm{L}$ after correction for glycemia. Hypovolemia was considered when three or more of the following symptoms/signs were observed: thirst, orthostatic symptoms, blood pressure $\leq 90 / 60 \mathrm{mmHg}$, heart rate $\geq 90 \mathrm{bpm}$, urinary sodium $\leq 30 \mathrm{mmol} / \mathrm{L}[5,6]$ or a rise in serum creatinine (SC) and/or serum urea (SU) accompanying the descent in $\mathrm{SNa}[7,8]$. The absence of the previous criterion was assumed as euvolemia. Hypervolemia was considered present when explicit signs of hydric overload or edematous heart failure were registered in the clinical records.

Variables were collected from admission day, 2nd -3th day of hospitalization, 7th -10th day of hospitalization, and from the day of discharge of the patients, when available. Data was collected according to how it appeared registered in clinical records. Collected variables were age, sex, SNa, serum potassium (SK), SC, SU, volemia, serum inflammatory markers (IM): D-dimer, fibrinogen, C-reactive protein, ferritin, lactate dehydrogenase, IL-6; comorbidities: obesity, hypertension, diabetes mellitus, chronic obstructive pulmonary disease/smoke habit, obstructive sleep apnea/hypopnea syndrome, asthma, pulmonary fibrosis, any cancer, obstructive uropathy and advanced/moderate chronic kidney disease (glomerular filtration rate $<60 \mathrm{ml} / \mathrm{min}$ ); previous drug use, and the clinical outcomes: hospital death, admittance to the intensive care unit (ICU), and length of hospital stay (LOS). Treatment variables 
were not collected since an important heterogeneity and a lack of details of this variable were observed during the review of the clinical records, therefore, this data would have had no value.

\section{Statistical analysis}

Univariate analysis for quantitative variables was developed with Mann-Whitney $\mathrm{U}$ or Kruskal-Wallis tests (when non-parametric) and T-student or ANOVA tests (when parametric). Univariate analysis for categorical variables was performed with Chi-squared or Fisher tests. Correlation studies with Pearson and Spearman tests were executed for quantitative variables.

Multivariate analyses with logistic regressions and Cox regression including variables with a $p$ value $<0.1$ in the univariate analysis and others of clinical relevance, were tested to evaluate the association of the variables with clinical outcomes, calculating odd ratio (OR) and Hazard ratio (HR) respectively. Multivariate analysis was developed with the forward steps Wald's method. A two-tailed $p$ value $<0.05$ was considered statistically significant. Ninety-five percent confidence intervals $(95 \% \mathrm{Cl})$ were calculated. Statistical analysis was performed using SPSS version 25 (IBM Corp., N.Y., USA).

\section{Ethical issues}

The study complied with accepted standards of good clinical practice of the World Medical Association Declaration of Helsinki, in accordance with the guidelines of the local Research Ethics Committee.

\section{Results}

A total of 172 patients with COVID-19 pneumonia were attended in the 3 wards by the respective COVID19 teams. Of them, hyponatremia was observed in 49 (28.5\%) patients. No data suggesting "hypervolemia" or registered as such was found in the clinical records of these patients. Whereas the data of hypovolemia was found in 27/49 (55.1\%) and of euvolemia in 22/49 (44.9\%) patients. The rate of cases with $\mathrm{SNa}<130 \mathrm{mmol} / \mathrm{L}$ at admission were similar between hypovolemic and euvolemic (22.2 vs. $18.2 \%, p=1)$. No patient in the entire group had $\mathrm{SNa}<125 \mathrm{mmol} / \mathrm{L}$ at admission. Thirty-four of the 49 patients (69.4) were treated with systemic glucocorticoids during the first week of the hospitalization. The patients' general characteristics at admission grouped according to volemic status are described in Table 1. 
Table 1

General characteristics of patients at admission

\begin{tabular}{|c|c|c|c|c|}
\hline & $\begin{array}{l}\text { Total cases } \\
(\mathrm{N}=49)\end{array}$ & $\begin{array}{l}\text { Hypovolemic } \\
(\mathrm{N}=27)\end{array}$ & $\begin{array}{l}\text { Euvolemic } \\
(\mathrm{N}=22)\end{array}$ & $p$ \\
\hline Age, years & $69.9 \pm 14.7$ & $64.9 \pm 14.5$ & $76.2 \pm 12.6$ & $0.006^{*}$ \\
\hline$>70$ years, $\mathrm{n}(\%)$ & $31(63.3)$ & $13(48.1)$ & $18(81.8)$ & $0.019 *$ \\
\hline Sex Male, n (\%) & $32(65.3)$ & $21(77.8)$ & $11(50)$ & $0.042^{*}$ \\
\hline Serum Sodium, mmol/L & $131.3 \pm 2.4$ & $130.8 \pm 2.3$ & $132 \pm 2.4$ & 0.084 \\
\hline Serum potassium, $\mathrm{mmol} / \mathrm{L}$ & $4.2 \pm 0.4$ & $4.2 \pm 0.4$ & $4.2 \pm 0.5$ & 0.882 \\
\hline Serum creatinine, $\mathrm{mg} / \mathrm{dL}$ & $0.9 \pm 0.4$ & $1.1 \pm 0.5$ & $0.7 \pm 0.3$ & $0.005^{*}$ \\
\hline Serum urea, $\mathrm{mg} / \mathrm{dL}$ & $39 \pm 18$ & $42 \pm 21$ & $34 \pm 12$ & 0.146 \\
\hline Glomerular filtration rate, $\mathrm{ml} / \mathrm{min}$ & $80 \pm 22$ & $76 \pm 23$ & $85 \pm 19$ & 0.126 \\
\hline \multicolumn{5}{|l|}{ COMORBIDITIES } \\
\hline Hypertension, n (\%) & $20(40.8)$ & $9(33.3)$ & $11(50)$ & 0.238 \\
\hline Obesity, n (\%) & $11(34.4)$ & $7(43.8)$ & $4(25)$ & 0.458 \\
\hline $\mathrm{DM}, \mathrm{n}(\%)$ & $8(16.3)$ & $5(18.5)$ & $3(13.6)$ & 0.715 \\
\hline Cancer, n (\%) & $8(16.3)$ & $5(18.5)$ & $3(13.6)$ & 0.715 \\
\hline Asthma, n (\%) & $5(10.2)$ & $3(11.1)$ & $2(9.1)$ & 1 \\
\hline COPD/Smoke habit, n (\%) & $4(8.2)$ & $3(11.1)$ & $1(4.5)$ & 0.617 \\
\hline OSAHS, n (\%) & $3(6.1)$ & $3(11.1)$ & 0 & 0.242 \\
\hline Obstructive uropathy, n (\%) & $3(6.1)$ & $2(7.4)$ & $1(4.5)$ & 1 \\
\hline Pulmonary Fibrosis, n (\%) & 0 & 0 & 0 & - \\
\hline Chronic kidney disease, $\mathrm{n}(\%)^{\S}$ & 0 & 0 & 0 & - \\
\hline \multicolumn{5}{|l|}{ PREVIOUS TREATMENT } \\
\hline ACEI, n (\%) & $10(20.4)$ & $4(14.8)$ & $6(27.3)$ & 0.311 \\
\hline ARB, n (\%) & $4(8.2)$ & $3(11.1)$ & $1(4.5)$ & 0.617 \\
\hline MRB, n (\%) & $1(2)$ & $1(3.7)$ & 0 & 1 \\
\hline Diuretics, n (\%) & 0 & 0 & 0 & - \\
\hline Antiepileptics, n (\%) & 0 & 0 & 0 & - \\
\hline Glucocorticoids, n (\%) & 0 & 0 & 0 & - \\
\hline
\end{tabular}




\begin{tabular}{|c|c|c|c|c|}
\hline & $\begin{array}{l}\text { Total cases } \\
(\mathrm{N}=49)\end{array}$ & $\begin{array}{l}\text { Hypovolemic } \\
(\mathrm{N}=27)\end{array}$ & $\begin{array}{l}\text { Euvolemic } \\
(\mathrm{N}=22)\end{array}$ & \\
\hline Heparin, n (\%) & 0 & 0 & 0 & \\
\hline Cotrimoxazole, n (\%) & $1(2)$ & $1(3.7)$ & 0 & \\
\hline Cyclosporine, n (\%) & 0 & 0 & 0 & \\
\hline Tacrolimus, n (\%) & 0 & 0 & 0 & \\
\hline Everolimus, n (\%) & 0 & 0 & 0 & \\
\hline \multicolumn{5}{|c|}{$\S$ Moderate/advance (glomerular filtration rate $<60 \mathrm{ml} / \mathrm{min}$ ) } \\
\hline \multicolumn{5}{|c|}{$\begin{array}{l}\text { ACEl: angiotensin-converting enzyme inhibitors, ARB: angiotensin-2 receptor blockers, MRB: } \\
\text { mineralocorticoid receptor blockers }\end{array}$} \\
\hline
\end{tabular}

\section{Clinical evolution}

During hospital evolution, hyponatremia rate progressively decreased from the 2 nd -3 th hospitalization day to the discharge of patients (Fig. 1). At the 2nd -3th hospitalization day, 17 (34.7\%) of the initial 49 patients were hyponatremic, and $11 / 42(26.2 \%)$ patients who remained hospitalized to the 7 th -10 th day, continued with hyponatremia. Of the 37 discharged patients, 8 (21.6\%) were hyponatremic. No significative differences between the rates of hypovolemic and euvolemic hyponatremia were encountered neither at the 2nd -3th hospitalization day nor at discharge day. However, at the 7th -10th hospitalization day, a higher rate of hyponatremic subjects were euvolemic $(27.3$ vs. $72.7 \%, p=0.043)$

In accordance to the univariate analysis, patients with obesity had a higher risk to remain hyponatremic at the 2nd -3th hospitalization day (OR $5.1,95 \% \mathrm{Cl}: 1.02$ to 25.54$)$, whereas those with chronic obstructive pulmonary disease/smoke habit were in a lower risk (OR $0.29,95 \% \mathrm{Cl}: 0.18$ to 0.46$)$. With the exception of volemic status at admission -as shown in previous paragraph-, nor the comorbidities nor previous treatment at admission, nor administration of glucocorticoids during hospitalization were associate with hyponatremia at 7th -10th day. Likewise, no difference of means or medians of IM was found between those who persisted with hyponatremia at 7th -10th day and those who did not.

On the end of the data collection, from the 49 initial followed patients, 37 (75.5\%) were discharged, with 2 (4.1\%) previously admitted to ICU, $5(10.2 \%)$ remained hospitalized, and 7 (14.3\%) dead. Death occurred before the 7th day in all these patients. Patients who dead were $>70$ years old, and 3 of them were hyponatremic at their 2 nd -3th hospitalization day.

No comorbidity or previous treatment at admission, neither sex, age, initial volemic status, IM at admission, hyponatremia at 2nd -3th day nor administration of glucocorticoids during hospitalization were statistically associated with death in the univariate analysis. In a multivariate analysis including 
age, sex, and the admission variables: SNa, D-Dimer, lactate dehydrogenase, and C-reactive protein, a higher SNa level was found to be independently associated with a decrease in the risk of mortality, both in Logistic regression (OR: $0.43,95 \% \mathrm{IC} .0 .20$ to $0.93, p=0.043$ ) and Cox regression (HR: 0.53, 95\% Cl:0.32 to $0.87, p=0.013)$. However, admission SC was a relevant factor for death in our patients, since when SC was added in the model of the previous Cox regression analysis, the $\mathrm{SNa}$ lost statistical significance. In this model, SC was the unique variable associate with death (HR: $12.23,95 \% \mathrm{Cl}: 2$ to $25.6, p=0.003$ ).

From the total of survivors, the LOS was 13.5 days [7.1-19.9]. A trend in a lower median LOS was found for hypovolemic compared to euvolemic (11 vs. 15 days, $p=0.546$ ). However, in the total group, nor a $\mathrm{SNa}<130 \mathrm{mmol} / \mathrm{L}$ at admission, nor the persistence of hyponatremia both at 2nd -3th and at 7th -10th hospitalization day were associated with a higher LOS.

\section{Inflammation status}

All patients in both volemic groups had at least one IM in high levels at admission. All patients had LDH levels $\geq 150 \mathrm{UI} / \mathrm{L}, 89.5 \%$ had Ferritin $\geq 250 \mathrm{ng} / \mathrm{mL}, 71.4 \%$ had C-reactive protein $\geq 5 \mathrm{mg} / \mathrm{L}, 74.4 \%$ had DDimer $\geq 500 \mathrm{ng} / \mathrm{mL}$, and $91.2 \%$ had Fibrinogen $\geq 450 \mathrm{mg} / \mathrm{dL}$. Only in 14/49 patients, IL- 6 was measured at admission, in $64.3 \%$ of them it was $\geq 10 \mathrm{pg} / \mathrm{mL}$. No differences of the medians of the IM at admission were found between hypovolemic and euvolemic (Table 2). We did not find significant correlations between IM levels and SNa at admission when all patients were analyzed together. However, SNa from hypovolemic patients was correlated with their fibrinogen levels at admission $(r:-529, p=0.035)$. 
Table 2

Comparison of the inflammatory markers between hypovolemic and euvolemic at admission and at the 7th -10th hospitalization day

\begin{tabular}{|c|c|c|c|}
\hline & $\begin{array}{l}\text { Hypovolemic } \\
(\mathrm{N}=27)\end{array}$ & $\begin{array}{l}\text { Euvolemic } \\
(\mathrm{N}=22)\end{array}$ & $p$ \\
\hline \multicolumn{4}{|l|}{ At the ADMISSION DAY } \\
\hline C-reactive protein, $\mathrm{mg} / \mathrm{L}$ & $14.2[4.8-19.6]$ & $7.7[4.1-23.6]$ & 0.191 \\
\hline D-Dimer ng/mL & 524 [279-1249] & $1106[629-3521]$ & 0.095 \\
\hline Lactate dehydrogenase, UI/L & $385[280-680]$ & $395[332-566]$ & 0.768 \\
\hline Ferritin, $\mathrm{ng} / \mathrm{mL}$ & 1148 [444-1745] & 547 [265-1409] & 0.330 \\
\hline Fibrinogen, mg/dL & $773[571-954]$ & $672[560-725]$ & 0.303 \\
\hline Interleuikin-6, pg/mL $\mathrm{m}^{\S}$ & 77 [57-83] & $16[5-86]$ & 0.07 \\
\hline \multicolumn{4}{|c|}{ At the 7th -10th HOSPITALIZATION DAY } \\
\hline C-reactive protein, $\mathrm{mg} / \mathrm{L}$ & $1.3[0.6-5.6]$ & $0.9[0.5-2.7]$ & 0.613 \\
\hline D-Dimer $\mathrm{ng} / \mathrm{mL}$ & $925[583-2652]$ & 749 [429-1438] & 0.26 \\
\hline Lactate dehydrogenase, UI/L & $342[256-723]$ & $307[232-418]$ & 0.129 \\
\hline Ferritin, ng/mL & 1066 [770-1771] & 484 [306-1363] & 0.116 \\
\hline Fibrinogen, mg/dL & $568[422-676]$ & $477[390-533]$ & 0.747 \\
\hline Interleuikin-6, pg/mL§§ & 880 [range 9.7-1751] & 143 [range:6.2-395] & 0.8 \\
\hline \multicolumn{4}{|c|}{ SOnly 14 patients had IL-6 measurements (4 in hypovolemic and 10 in euvolemic) } \\
\hline
\end{tabular}

We observed that C-reactive protein, lactate dehydrogenase and fibrinogen levels statistically decreased from admission to the 7th -10th hospitalization day in the entire cohort (Table 3). Parallelly, an increase in $\mathrm{SNa}$ levels as well as a reduction in the hyponatremia rate was also observed at the same time. However, we did also not encounter correlations between IM levels and SNa at the 7th -10th hospitalization day, nor when patients were analyzed in the global cohort nor when were analyzed according to their initial volemic status. 
Table 3

Evolution of the Inflammatory markers and serum sodium in the global of patients from the admission to the 7th -10th hospitalization day

\begin{tabular}{|c|c|c|c|}
\hline & At admission day & At the 7th -10 th hospitalization day & $p$ \\
\hline C-reactive protein, $\mathrm{mg} / \mathrm{L}$ & $8.4[4.5-23]$ & $0.9[0.5-3.3]$ & $<0.001^{\star}$ \\
\hline D-Dimer $\mathrm{ng} / \mathrm{mL}$ & 815 [440-2398] & $865[529-177]$ & 0.26 \\
\hline Lactate dehydrogenase, UI/L & 395 [299-582] & 337 [254-493] & $0.008^{*}$ \\
\hline Ferritin, ng/mL & 973 [334-1525] & $973[396-1568]$ & 0.22 \\
\hline Fibrinogen, mg/dL & $683[565-810]$ & $503[393-671]$ & $0.012^{*}$ \\
\hline Interleuikin-6, pg/mL $\S$ & $49[7-81]$ & 143 [8-1073] & 0.109 \\
\hline $\mathrm{SNa}, \mathrm{mmol} / \mathrm{L}$ & $132[130-133]$ & $136[134-138]$ & $<0.001^{*}$ \\
\hline Hyponatremia, n (\%) & $49 / 49(100)$ & $11 / 42(26.2)$ & $<0.001 *$ \\
\hline \multicolumn{4}{|c|}{$\begin{array}{l}\text { SOnly } 14 \text { patients at the admission day and } 5 \text { at the } 7^{\circ}-10^{\circ} \text { day had IL-6 measurements. } \\
\star_{p}<0.05\end{array}$} \\
\hline
\end{tabular}

Although IM levels had a trend to be higher in hypovolemic than euvolemic at the 7th -10th hospitalization day, no statistical differences were found (Table 2). Furthermore, in the 11 patients who remained hyponatremic at the 7th -10th hospitalization day, no correlation was found between IM levels and SNa.

\section{Discussion}

The results of the current study suggest that the evolution of both hypovolemic or euvolemic hyponatremia during the hospitalization of the patients with COVID-19 pneumonia is linked to their inflammatory status. Indeed, the decrement of IM levels during hospitalization was accompanied by an increase in $\mathrm{SNa}$ and a reduction in the rate of hyponatremia at the same time. This permits us, therefore, hypothesize that the presence of hyponatremia in COVID-19 patients, either hypovolemic or euvolemic, could depend of the inflammation generated in these patients.

As in pneumonia caused by other infections $(11,12)$, hyponatremia is also a risk factor for a poor hospital prognosis in patients with COVID-19 pneumonia $(4,5,9,13)$. In fact, a lower SNa at admission have been related with a higher risk for mortality(5). The current study found similar results. Although most of the patients in our cohort had mild hyponatremia, with no patient with SNa below $125 \mathrm{mmol} / \mathrm{L}$, we observed that per each increment in $\mathrm{mmol} / \mathrm{L}$ of $\mathrm{SNa}$ at admission, the risk of mortality reduced by a $57 \%$. However, the mechanisms behind the impact of the decreased SNa levels or hyponatremia on hospital mortality are totally elucidated. 
A common discussion is about whether hyponatremia, especially when mild, is a direct cause for increased mortality risk or whether it is only another "indicator" of a worse clinical situation. Based on our results, we hypothesize that the latter would be the most probable setting, and some findings of our study support that idea. First, we observed a parallel decrement of the rate of hyponatremia as IM levels were decreasing. This suggests that an inflammatory status could predispose to the development of hyponatremia and that the degree of hyponatremia could be a reflection of the degree of the inflammation. Thus, when inflammation decreases, a recovering in the water/sodium balance would be expected, as did in our cohort. Inflammatory pathways via different cytokines, such as tumoral-necrosis factor-a, IL-1 or IL6, are involved in a non-osmotic release of arginine-vasopressin(14). In fact, it has been reported that the risk of hyponatremia is higher in the setting of an acute inflammatory phase, especially when patients are receiving hypotonic fluids $(15,16)$, indicating an inadequate antidiuresis. Beukhof et al. in a case-control study of patients with hyponatremia, observed that those who developed hyponatremia had a coincident increase in C-reactive protein levels(16). Likewise, IL-6, a usual IM, has been strongly corelated with arginine-vasopressin concentrations in blood, and directly related with the development of SIADH, both in children (17) and adults $(18,19)$. Recently, Berni et al. (9) found an inverse moderate correlation between IL-6 levels and SNa in 29 COVID-19 patients. Furthermore, they observed a significative increment of SNa when hyponatremic patients with elevated IL-6 levels were treated with tocilizumab (humanized monoclonal antibody against the IL- 6 receptor). Second, we found that patients who remained hyponatremic during hospitalization were not at high risk of death. This is in contrast with the expected if mild hyponatremia could induce a direct damage and therefore increases the mortality risk. And third, the early death of the patients, with only $3 / 7$ of them with hyponatremic at the 2nd -3th hospitalization day, suggests that the clinical severity was principally caused by COVID-19 pneumonia itself rather than hyponatremia. Therefore, in agreement with Berni et al., we suspect that hyponatremia is another sign of a major severity in COVID-19 patients, which is depending of the inflammatory involvement affecting respiratory function. In fact, higher respiratory rates(4,5)and lower oxygen levels(4) have been reports as more frequent in hyponatremic than eunatremic COVID-19 patients.

However, we cannot deny that even mild hyponatremia could impair the metabolic cellular response to inflammation in different tissues, and therefore, perpetuate the damage already stablished by the inflammation itself. Thus, the role of hyponatremia seems to be more complex. In fact, in the HOPECOVID-19 study(5) -with a predominantly mild hyponatremia cohort- hyponatremia was also associated with a higher risk for sepsis. Furthermore, in that study the combination of sepsis with hyponatremia increased the mortality risk of these patients(5). Sepsis, as an inflammatory status, can cause $\mathrm{Na}+$ and $\mathrm{Ca}++$ channel dysfunction (20). Hyponatremia itself can also alter the normal function of $\mathrm{Na}+\mathrm{and} \mathrm{Ca}+$ + channels $(21,22)$.A combination of both factors could thus harm the mechanisms of voltage-dependent cellular conduction and therefore impair several cellular functions, which can lead to organ/tissue dysfunction (e.g., in the kidney(23)) and consequently induce multi-organ failure. Therefore, we encourage physicians to properly correct hyponatremia in all clinical situations.

One would expected that SIADH, an euvolemic hyponatremia is the main cause of hyponatremia in COVID-19 patients, as some authors have proposed (8). Furthermore, it would be in accordance with the 
commented above. However, we find a similar rate of hypovolemic and euvolemic hyponatremia. Unfortunately, our study lacked the power to determine specific etiologies of hyponatremia, since nor adrenal axis nor the withdrawal of SIADH-related drugs, nor urine ions studies, nor data of clinical losses of volemia were fully evaluated and registered in the clinical records of our cohort. Nevertheless, the fact that the IM levels were similar between hypovolemic and euvolemic, both at admission and at 7th -10th hospitalization day, indicates that in both types of hyponatremia, the inflammatory status played a similar role. Therefore, although other factors may be involved in the development of hyponatremia depending on whether it is hypovolemic or euvolemic, it is a fact, in our opinion, that the inflammatory status of patients with COVID-19 pneumonia would favor its presence.

A weakness of the study is the size of the series. Other is the lack of a more detailed information about hospital treatment of the patients. However, at that moment of the pandemic, different protocols were used in different hospital, so these data would have been heterogeneous and biased. Nevertheless, the current data was enough to permit the main objective to be evaluated. Unfortunately, IL-6 was not measured in all patients, which decreased the statistical potency to assay this variable. Likewise, no hypervolemic hyponatremia was encountered in our registry, therefore whether hypervolemic hyponatremia has the same inflammatory characteristics than hypovolemic or euvolemic hyponatremia remains unknown. The main strength is that this study highlights the role of hyponatremia as a clinical marker of severity and inflammation in COVID-19 patients, which could help physicians stratify patient risk in order to take clinical decisions.

In conclusion, in our COVID-19 series, the evolution of admission hyponatremia during the hospitalization coincided with the improvement of IM levels. This evolution was similar in both hypovolemic and euvolemic hyponatremia. Therefore, the implication of the inflammatory status on the development of hyponatremia in COVID-19 patients is proposed.

\section{Declarations}

\section{Funding:}

JGRS has a contract as a researcher with the Foundation for Biomedical Research at the Hospital Clínico San Carlos (Reference number. INV-15-2019). But this research received no external funding.

\section{Conflicts of Interest:}

Conflict of Interest: The authors declare that they have no conflict of interest.

\section{Author Contributions:}

Conceptualization: JGR-S; Methodology: JGR-S, JC-S, Validation: JGR-S, PC-D, JC-S; Formal analysis: JGR-S, JC-S; Investigation: JGR-S, PC-D, JC-S; Writing - Original Draft Preparation: JGR-S; Writing Review \& Editing: JGR-S, PC-D, JC-S; Supervision and reviewing: JGR-S; Resources: JGR-S, PC-D, JC-S. All authors have read and agreed to the published version of the manuscript. 


\section{Ethics approval:Consent to participate}

The study complied with accepted standards of good clinical practice of the World Medical Association Declaration of Helsinki, in accordance with the guidelines of the local Research Ethics Committee.

\section{Consent to participate:}

Not applicable

\section{Consent for publication:}

Not applicable.

\section{References}

1. Waikar SS, Mount DB, Curhan GC. Mortality after Hospitalization with Mild, Moderate, and Severe Hyponatremia. Am J Med [Internet]. 2009 Sep;122(9):857-65. Available from: https://linkinghub.elsevier.com/retrieve/pii/S0002934309002800

2. Wald R. Impact of Hospital-Associated Hyponatremia on Selected Outcomes. Arch Intern Med [Internet]. 2010 Feb 8;170(3):294. Available from: http://archinte.jamanetwork.com/article.aspx? doi=10.1001/archinternmed.2009.513

3. Cuesta M, Slattery D, Goulden EL, Gupta S, Tatro E, Sherlock M, et al. Hyponatraemia in patients with community-acquired pneumonia; prevalence and aetiology, and natural history of SIAD. Clin Endocrinol (Oxf) [Internet]. 2019 May 18;90(5):744-52. Available from: https://onlinelibrary.wiley.com/doi/abs/10.1111/cen.13937

4. Atila C, Sailer CO, Bassetti S, Tschudin-Sutter S, Bingisser R, Siegemund M, et al. Prevalence and outcome of dysnatremia in patients with COVID-19 compared to controls. Eur J Endocrinol [Internet]. 2021 Mar;184(3):413-22. Available from: https://eje.bioscientifica.com/view/journals/eje/184/3/EJE-20-1374.xml

5. Ruiz-Sánchez JG, Núñez-Gil IJ, Cuesta M, Rubio MA, Maroun-Eid C, Arroyo-Espliguero R, et al. Prognostic Impact of Hyponatremia and Hypernatremia in COVID-19 Pneumonia. A HOPE-COVID-19 (Health Outcome Predictive Evaluation for COVID-19) Registry Analysis. Front Endocrinol (Lausanne) [Internet]. 2020 Nov 30;11. Available from: https://www.frontiersin.org/articles/10.3389/fendo.2020.599255/full

6. Hu W, Lv X, Li C, Xu Y, Qi Y, Zhang Z, et al. Disorders of sodium balance and its clinical implications in COVID-19 patients: a multicenter retrospective study. Intern Emerg Med [Internet]. 2020 Oct 16; Available from: http://link.springer.com/10.1007/s11739-020-02515-9

7. Frontera JA, Valdes E, Huang J, Lewis A, Lord AS, Zhou T, et al. Prevalence and Impact of Hyponatremia in Patients With Coronavirus Disease 2019 in New York City. Crit Care Med [Internet]. 2020 Dec 20;48(12):e1211-7. Available from: https://journals.Iww.com/10.1097/CCM.0000000000004605 
8. Gheorghe G, Ilie M, Bungau S, Stoian AMP, Bacalbasa N, Diaconu CC. Is There a Relationship between COVID-19 and Hyponatremia? Medicina (B Aires) [Internet]. 2021 Jan 9;57(1):55. Available from: https://www.mdpi.com/1648-9144/57/1/55

9. Berni A, Malandrino D, Parenti G, Maggi M, Poggesi L, Peri A. Hyponatremia, IL-6, and SARS-CoV-2 (COVID-19) infection: may all fit together? J Endocrinol Invest [Internet]. 2020 Aug 25;43(8):1137-9. Available from: http://link.springer.com/10.1007/s40618-020-01301-w

10. Mastorakos G, Weber JS, Magiakou MA, Gunn H, Chrousos GP. Hypothalamic-pituitary-adrenal axis activation and stimulation of systemic vasopressin secretion by recombinant interleukin- 6 in humans: potential implications for the syndrome of inappropriate vasopressin secretion. J Clin Endocrinol Metab [Internet]. 1994 Oct;79(4):934-9. Available from: https://academic.oup.com/jcem/article-lookup/doi/10.1210/jcem.79.4.7962300

11. Müller M, Schefold JC, Guignard V, Exadaktylos AK, Pfortmueller CA. Hyponatraemia is independently associated with in-hospital mortality in patients with pneumonia. Eur J Intern Med [Internet]. 2018 Aug;54:46-52. Available from: https://linkinghub.elsevier.com/retrieve/pii/S095362051830147X

12. Nair V, Niederman MS, Masani N, Fishbane S. Hyponatremia in Community-Acquired Pneumonia. Am J Nephrol [Internet]. 2007;27(2):184-90. Available from:

https://www.karger.com/Article/FullText/100866

13. De Carvalho H, Letellier T, Karakachoff M, Desvaux G, Caillon H, Papuchon E, et al. Hyponatremia is associated with poor outcome in COVID-19. J Nephrol [Internet]. 2021 Apr 7; Available from: http://link.springer.com/10.1007/s40620-021-01036-8

14. Swart RM, Hoorn EJ, Betjes MG, Zietse R. Hyponatremia and Inflammation: The Emerging Role of Interleukin-6 in Osmoregulation. Nephron Physiol [Internet]. 2011;118(2):p45-51. Available from: https://www.karger.com/Article/FullText/322238

15. Ferreira da Cunha D, Pontes Monteiro J, Modesto dos Santos V, Araújo Oliveira F, Freire de Carvalho da Cunha S. Hyponatremia in Acute-Phase Response Syndrome Patients in General Surgical Wards. Am J Nephrol [Internet]. 2000;20(1):37-41. Available from:

https://www.karger.com/Article/FullText/13553

16. Beukhof CM, Hoorn EJ, Lindemans J, Zietse R. Novel risk factors for hospital-acquired hyponatraemia: a matched case?control study. Clin Endocrinol (Oxf) [Internet]. 2007 Mar;66(3):36772. Available from: http://doi.wiley.com/10.1111/j.1365-2265.2007.02741.x

17. Gionis D, Ilias I, Moustaki M, Mantzos E, Papadatos I, Koutras DA, et al. Hypothalamic-PituitaryAdrenal Axis and Interleukin-6 Activity in Children with Head Trauma and Syndrome of Inappropriate Secretion of Antidiuretic Hormone. J Pediatr Endocrinol Metab [Internet]. 2003 Jan;16(1). Available from: https://www.degruyter.com/document/doi/10.1515/JPEM.2003.16.1.49/html

18. MURAKAMI T, MATOBA H, KUGA Y, OZAWA S, KUBOTA K, YOSHIDA S. Hyponatremia in a Patient with Chronic Inflammatory Disease. Intern Med [Internet]. 1998;37(9):792-5. Available from: http://joi.jlc.jst.go.jp/JST.Journalarchive/internalmedicine1992/37.792?from=CrossRef 
19. Ota $K$, Kumon Y, Hashimoto K. Unexpected impaired consciousness in RA: a rare complication of SIADH induced by increased IL-6. Clin Exp Rheumatol [Internet]. 22(1):134. Available from: http://www.ncbi.nlm.nih.gov/pubmed/15005020

20. Rossignol B, Gueret G, Pennec J-P, Morel J, Giroux-Metges MA, Talarmin H, et al. Effects of chronic sepsis on the voltage-gated sodium channel in isolated rat muscle fibers*. Crit Care Med [Internet]. 2007 Feb;35(2):351-7. Available from: http://journals.Iww.com/00003246-200702000-00002

21. Ayaz M, Karabagli H, Yanardag SB. Can Hypo/Hypernatremic Conditions be a Factor for Na Ion Channel Kinetics: Model Study. Turk Neurosurg [Internet]. 2018;28(3):421-7. Available from: http://www.ncbi.nlm.nih.gov/pubmed/28585673

22. Squecco R, Luciani P, Idrizaj E, Deledda C, Benvenuti S, Giuliani C, et al. Hyponatraemia alters the biophysical properties of neuronal cells independently of osmolarity: a study on $\mathrm{Ni} 2+$-sensitive current involvement. Exp Physiol [Internet]. 2016 Aug 1;101(8):1086-100. Available from: http://doi.wiley.com/10.1113/EP085806

23. Sanz AB, Sanchez-Niño MD, Ortiz A. TWEAK, a multifunctional cytokine in kidney injury. Kidney Int [Internet]. 2011 Oct;80(7):708-18. Available from:

https://linkinghub.elsevier.com/retrieve/pii/S008525381555117X

\section{Figures}

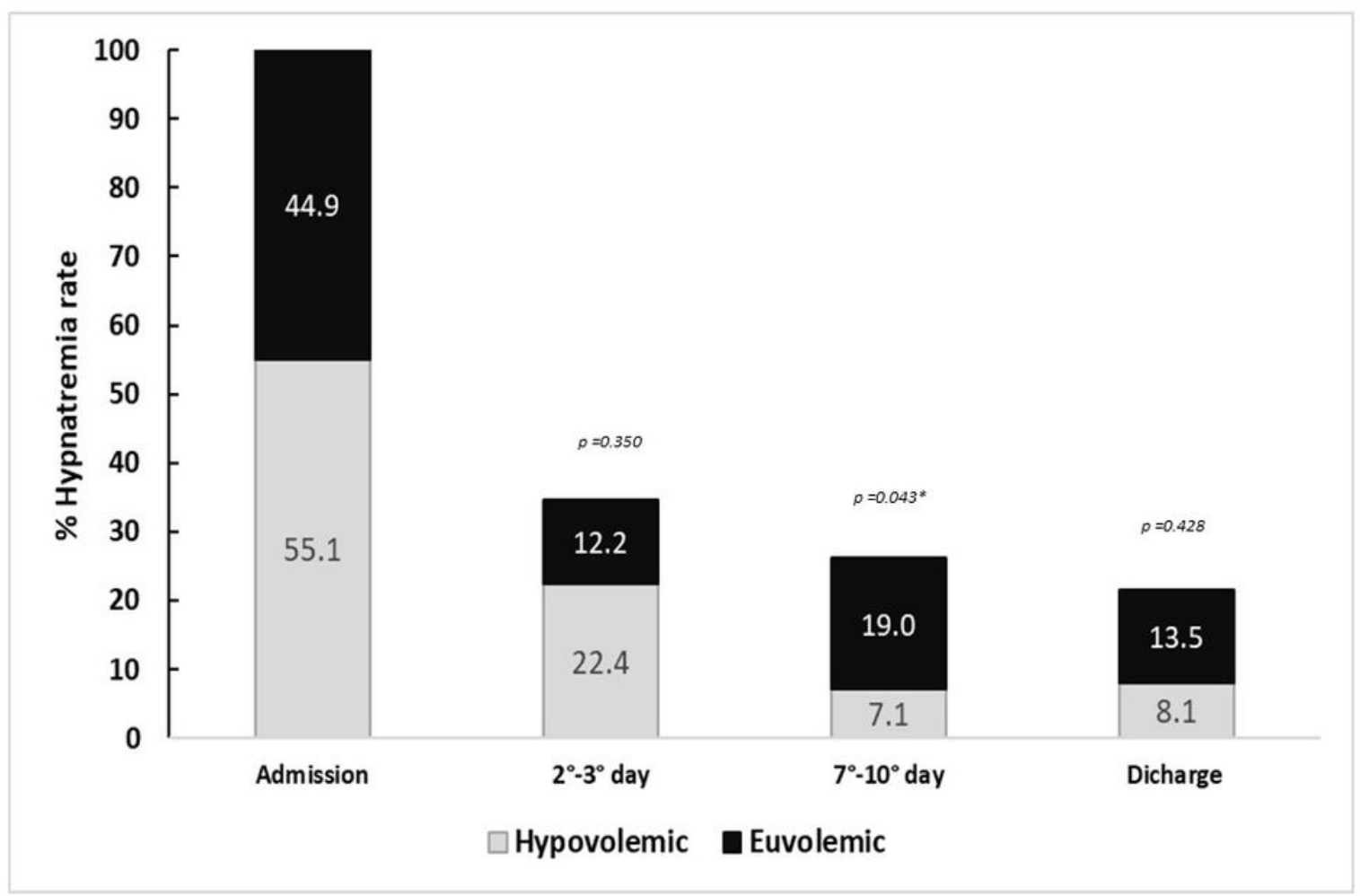

Figure 1 
Evolution of hyponatremia rates during hospitalization, grouped as hypovolemic and euvolemic. 